\title{
Randomised controlled trials in plastic surgery: a systematic review of reporting quality
}

\author{
Riaz Ahmed Agha • Christian F. Camm • \\ Emre Doganay • Eric Edison • \\ Muhammed R. S. Siddiqui • Dennis P. Orgill
}

Received: 31 May 2013 / Accepted: 9 September 2013 /Published online: 30 October 2013

(C) Springer-Verlag Berlin Heidelberg 2013

\begin{abstract}
Background We recently conducted a systematic review of the methodological quality of randomised controlled trials (RCTs) in plastic surgery. In accordance with convention, we are here separately reporting a systematic review of the reporting quality of the same RCTs.

Methods MEDLINE ${ }^{\circledR}$ and the Cochrane Database of Systematic Reviews were searched by an information specialist from 1 January 2009 to 30 June 2011 for the MESH heading 'Surgery, Plastic'. Limitations were entered for English language, human studies and randomised controlled trials. Manual searching for RCTs involving surgical techniques was performed within the results. Scoring of the eligible papers was performed against the 23-item CONSORT Statement checklist.
\end{abstract}

\footnotetext{
R. A. Agha $(\bowtie)$

Department of Plastic Surgery, Stoke Mandeville Hospital,

Aylesbury, Bucks, UK

e-mail: mail@riazagha.com

C. F. Camm

Department of Trauma, Emergency, and Acute Medicine, King's

College Hospital, London, UK

E. Doganay

Department of Clinical Medicine, University of Southampton,

Southampton, UK

E. Edison

Department of Clinical Medicine, University College London,

London, UK

M. R. S. Siddiqui

Department of Surgery, Epsom and St Heliers Hospital, Surrey, UK

D. P. Orgill

Division of Plastic Surgery, Department of Surgery, Brigham and Women's Hospital and Harvard Medical School, Boston, MA, USA
}

Independent secondary scoring was then performed and discrepancies resolved through consensus.

Results Fifty-seven papers met the inclusion criteria. The median CONSORT score was 11.5 out of 23 items (range 5.3-21.0). Items where compliance was poorest included intervention/comparator details (7\%), randomisation implementation (11\%) and blinding (26\%). Journal 2010 impact factor or number of authors did not significantly correlate with CONSORT score (Spearman rho $=0.25$ and 0.12 , respectively). Only $61 \%$ declared conflicts of interest, $75 \%$ permission from an ethics review committee, $47 \%$ declared sources of funding and $16 \%$ stated a trial registry number. There was no correlation between the volume of RCTs performed in a particular country and reporting quality.

Conclusions The reporting quality of RCTs in plastic surgery needs improvement. Better education, awareness amongst all stakeholders and hard-wiring compliance through electronic journal submission systems could be the way forward. We call for the international plastic surgical community to work together on these long-standing problems.

Keywords Randomised controlled trials $\cdot$ Research methodology $\cdot$ Reporting quality $\cdot$ Consort $\cdot$ Levels of evidence

\section{Introduction}

Randomised controlled trials (RCTs) represent the criterion standard in evaluating healthcare interventions. However, RCTs can yield biased results if they lack methodological rigour [1], especially where surgical techniques are involved [2]. Readers need complete, clear and transparent information in order to assess a trial accurately. Unfortunately, many trials fail to 
provide critical information in published reports [3-5]. Inadequately reported RCTs are associated with bias in estimating the effectiveness of interventions and with poor methodology [6-12].

The Consolidated Standards of Reporting Trials statement was originally developed in 1996 [13] to aid reporting of RCTs, and an extension for non-pharmacological interventions (CONSORT NPT) was published in 2008 [14]. It consists of a 23 -item checklist and flow diagram.

Our team have previously assessed the methodological quality of recent RCTs in plastic surgery, concluding that it requires improvement [15]. However, although flaws in methodology limit the validity and generalizability of study results, without accurate reporting, shortcomings in study design and implementation can be compounded and become difficult to accurately assess. Studies looking at methodological quality are usually separate from reporting quality [16]. Given this previous work, the purpose of this new study is to systematically review the reporting quality of recent RCTs in plastic surgery using CONSORT NPT criteria. This new work will allow the plastic surgical community to take stock of where reporting quality has been in recent years.

\section{Material and methods}

Search methods

The search technique was the same as used for this team's previous work assessing the methodological quality of plastic surgery RCTs [15]. An information specialist (trained in database searching by NHS Evidence, who conducts approximately 100 searches per year and is the staff trainer) based at the lead authors Plastic Surgery Unit searched MEDLINE ${ }^{\circledR}$ and the Cochrane Database of Systematic Reviews from 1 January 2009 to 30 June 2011 for the Medical Subject Headings (MESH is the NLM controlled vocabulary thesaurus used for indexing articles for PubMed) 'Surgery, Plastic' or 'Reconstructive Surgical Procedures' with 'or' used as a Boolean operator and with the 'explode' function activated. We chose this time period since the CONSORT NPT statement was only published in 2008 and hence it would be unfair to hold RCTs prior to this period to a standard that did not exist at the time of writing. Limitations were set for the English language, human studies and randomised controlled trials.

Results were then manually searched by four of us (ED, MS, CFC and EE) for relevant RCTs involving surgical techniques. Papers involving purely pharmacological therapies in all arms, cost analyses, study protocols, interim or non-randomised studies, short communications and RCTs involving virtual or simulated procedures were excluded.
Scoring

The papers were then scored by one of three primary scorers (ED, MS, EE) against the 23-item CONSORT NPT checklist with each item being given an equal weighting. Items 4 and 11 were subdivided into four and three sub-parts, respectively; a full point was only gained if all sub-parts were fulfilled; otherwise, the appropriate fraction was awarded. The resulting mark out of 23 was termed the 'CONSORT score'. Following this initial round of scoring (ED scored 2009, MS scored 2010 and 2011), all papers were then rescored by a single secondary scorer (CFC). Discrepancies were then resolved by consensus (between ED, MS and CFC), and if that could not be reached, they were referred to the lead author (RA) for a final judgement. Evaluators were not blinded to the country of origin of the authors.

Compliance with individual items of the statement was analysed (by summating the number of articles fulfilling that item divided by the total number of included articles) as well as the relationship between CONSORT score and year of publication, geographical origin (for the RCT), the number authors and the ISI 2010 impact factor for the journals in which the RCTs were published. These additional correlates were chosen to give information about whether improvements are occurring over time and whether volume and perceived markers of RCT quality (like impact factor of the journal in which it is published) correlate with actual reporting quality as defined by CONSORT.

\section{Secondary analyses}

In addition to the CONSORT score, papers were assessed for whether they fulfilled seven additional criteria referred to in the CONSORT NPT and whether they mention conflicts of interest, sources of finding, a trial registry number and ethical approval.

\section{Statistical analysis}

In line with previous work [15], inter-rater agreement was assessed using the Kappa score. Data were analysed using non-parametric descriptors such as median, and correlations were calculated using Spearman rho, using SPSS version 20.

\section{Results}

The search history was as follows:

1. MEDLINE; exp SURGERY, PLASTIC/; 25,698 results

2. MEDLINE; exp RECONSTRUCTIVE SURGICAL PROCEDURES/; 52,999 results

3. MEDLINE; 1 OR 2; 76,741 results 
Fig. 1 PRISMA flow diagram, illustrating how papers were selected (adapted from Moher et al. [17])
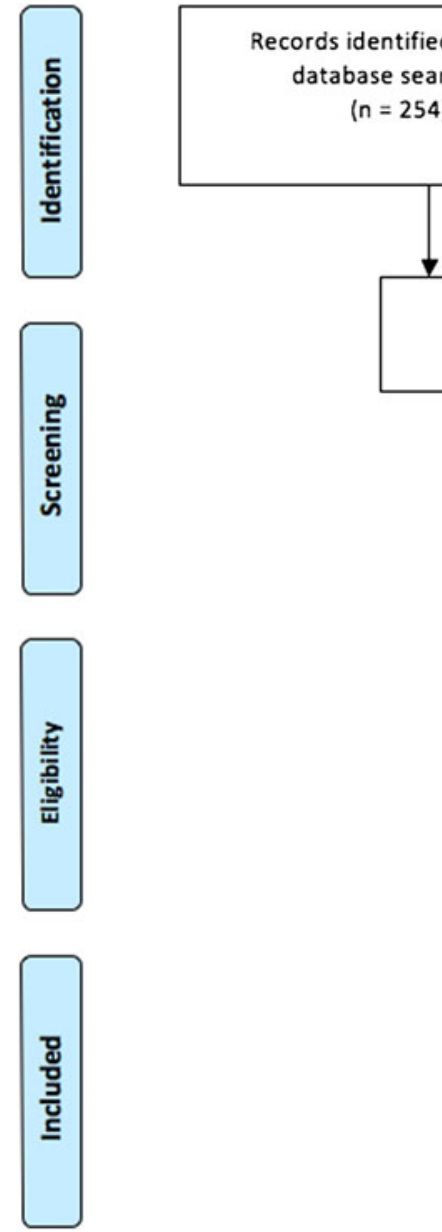

4. MEDLINE; 3 [Limit to: Publication Year 2009-2011 and English Language]; 11,395 results

5. MEDLINE; 4 [Limit to: (Publication Types Randomized Controlled Trial) and Publication Year 2009-2011 and English Language]; 254 results

From the initial set of 254 papers retrieved from MEDLINE, 63 were selected following a manual search and abstract assessment by the authors (ED, MS, CFC). Subsequent to complete download of all 63 papers, six were excluded for being a study protocol, purely pharmacological or theoretical, retrospective or an interim study. This resulted in 57 RCTs which met the inclusion criteria (seven were multicentre), published across 28 journals. All RCTs compared treatment interventions and none related to diagnosis. No further relevant trials were found in the Cochrane Database of Systematic Reviews (Fig. 1).

The median CONSORT score was 11.5 out of 23 items (range 4.5-21.0) with a Kappa score 0.80. There was a slight trend for improvement over the 3-year period, on average 1.5 CONSORT points per year (Spearman rho 0.999) (see Table 1).
Compliance with individual items of the CONSORT

Compliance was highly variable for the different CONSORT items. This is shown in Fig. 2. Compliance was the poorest for items related to intervention/comparator details (7\%), randomisation implementation (11\%) and blinding (26\%), as shown in Table 2.

Compliance with additional criteria

There was poor fulfilment of additional criteria and only $61 \%$ declared conflicts of interest, $75 \%$ permission

Table 1 Summary statistics for CONSORT scores per year

\begin{tabular}{llcc}
\hline Year & Number of RCTs & Median CONSORT score & Range \\
\hline 2009 & 26 & 9.9 & $4.5-17.3$ \\
2010 & 21 & 11.5 & $5.3-21.0$ \\
$2011^{\mathrm{a}}$ & 10 & 12.9 & $9.0-15.0$ \\
\hline
\end{tabular}

${ }^{\mathrm{a}}$ To 30 June 2011 only 
Fig. 2 Compliance of the 57 RCTs with the individual items of the CONSORT statement

Table 2 Compliance of RCTs with individual items of the CONSORT statement (ranked in order of increasing fulfilment)

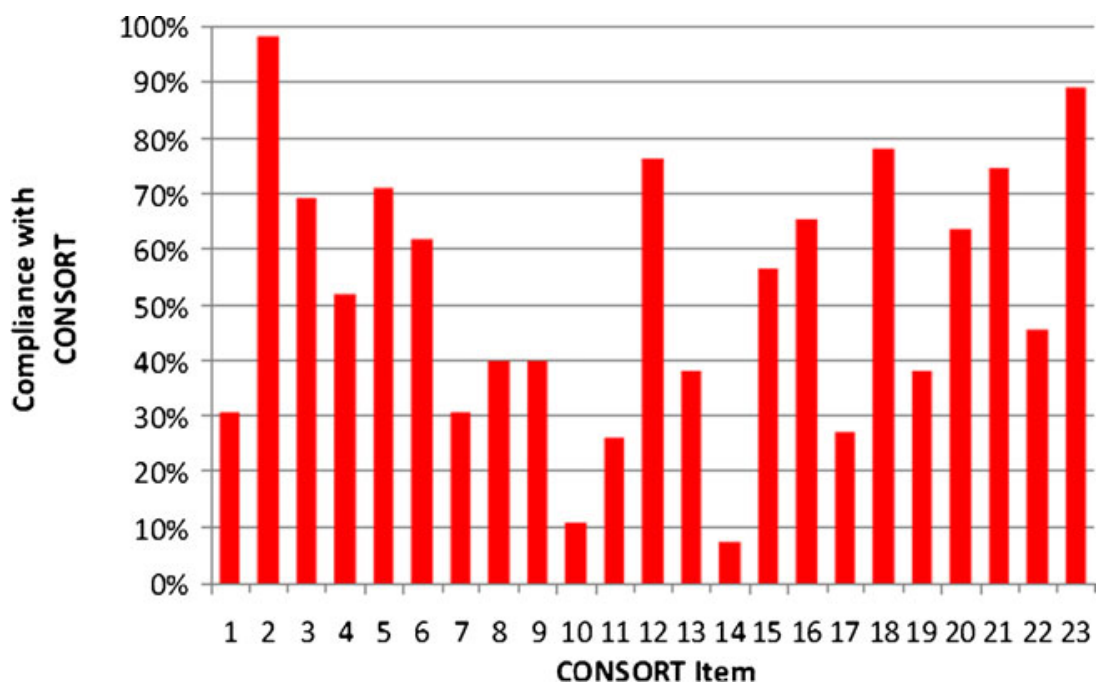

\begin{tabular}{|c|c|c|}
\hline Criteria & Abbreviated description & Compliance $(\%)$ \\
\hline New item $(23)$ & $\begin{array}{l}\text { Details of the experimental treatment and comparator as they were } \\
\text { implemented }\end{array}$ & 7 \\
\hline 10 & $\begin{array}{l}\text { Who generated the allocation sequence, who enrolled participants and } \\
\text { who assigned participants to their groups }\end{array}$ & 11 \\
\hline 11 & $\begin{array}{l}\text { Whether or not participants, those administering the interventions and } \\
\text { those assessing the outcomes were blinded to group assignment }\end{array}$ & 26 \\
\hline 16 & $\begin{array}{l}\text { Number of participants (denominator) in each group included in each } \\
\text { analysis and whether analysis was by 'intention-to-treat' }\end{array}$ & 27 \\
\hline 1 & $\begin{array}{l}\text { How participants were allocated to interventions - is it mentioned in } \\
\text { the title }\end{array}$ & 31 \\
\hline 7 & $\begin{array}{l}\text { How sample size was determined and, when applicable, explanation of } \\
\text { any interim analyses and stopping rules }\end{array}$ & 31 \\
\hline 13 & Flow of participants through each stage (a diagram is strongly recommended) & 38 \\
\hline 18 & $\begin{array}{l}\text { Address multiplicity by reporting any other analyses performed, including } \\
\text { subgroup analyses and adjusted analyses, indicating those prespecified } \\
\text { and those exploratory }\end{array}$ & 38 \\
\hline 8 & $\begin{array}{l}\text { Method used to generate the random allocation sequence, including details } \\
\text { of any restriction (e.g. blocking, stratification) }\end{array}$ & 40 \\
\hline 9 & $\begin{array}{l}\text { Method used to implement the random allocation sequence, clarifying } \\
\text { whether the sequence was concealed until interventions were assigned }\end{array}$ & 40 \\
\hline 21 & Generalizability (external validity) of the trial findings & 45 \\
\hline 4 & $\begin{array}{l}\text { Precise details of the interventions intended for each group and how and } \\
\text { when they were actually administered }\end{array}$ & 52 \\
\hline 14 & Dates defining the periods of recruitment and follow-up & 56 \\
\hline 6 & Clearly defined primary and secondary outcome measures & 62 \\
\hline 19 & All important adverse events or side effects in each intervention group & 64 \\
\hline 15 & Baseline demographic and clinical characteristics of each group & 65 \\
\hline 3 & $\begin{array}{l}\text { Eligibility criteria for participants and the settings and locations where } \\
\text { the data were collected }\end{array}$ & 69 \\
\hline 5 & Specific objectives and hypotheses & 71 \\
\hline 20 & $\begin{array}{l}\text { Interpretation of the results, taking into account study hypotheses, sources } \\
\text { of potential bias or imprecision }\end{array}$ & 75 \\
\hline 12 & $\begin{array}{l}\text { Statistical methods used to compare groups for primary outcome(s); } \\
\text { methods for additional analyses, such as subgroup analyses and } \\
\text { adjusted analyses }\end{array}$ & 76 \\
\hline 17 & $\begin{array}{l}\text { For each primary and secondary outcome, a summary of results for } \\
\text { each group and the estimated effect size and its precision }\end{array}$ & 78 \\
\hline 22 & General interpretation of the results in the context of current evidence & 89 \\
\hline 2 & Scientific background and explanation of rationale & 98 \\
\hline
\end{tabular}

Consort table adapted from Moher et al. [7] 
Table 3 Compliance of RCTs with additional criteria

Additional criteria $\quad$ Compliance (\%)

AD1 - eligibility criteria for care providers $\quad 7$

AD2 - details on the centres' volume 5

AD3 - number of care providers performing the 38 treatment in each group

AD4 - number of participants treated by each care 31 provider

AD5-details on patients' expectancies or preference 2

for the treatments at baseline

AD6 - baseline data of care providers

AD7-details on care providers' compliance with 4 the planned procedure

Ethical approval

Sources of funding

Trial registry number

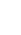

5

8

31

2

4

75

47

16

Conflicts of interest

61

from an ethics review committee, $47 \%$ declared sources of funding and just $16 \%$ stated a trial registry number (Table 3 ).

\section{CONSORT score and number of authors}

There was no correlation between number of authors and CONSORT score (Spearman rho $=0.12$, see Fig. 3 ).

\section{CONSORT score and impact factor}

There was no correlation between journal impact factor and CONSORT score (Spearman rho $=0.26$, see Fig. 4 ).

Geographical distribution of RCTs and CONSORT compliance

There was no correlation between the volume of RCTs conducted in a particular country and CONSORT score (Fig. 5).

\section{Discussion}

Over the last decade, there have been increasing calls for utilising an evidence-based medicine approach within surgery $[18,19]$. However, the evidence base in plastic surgery is still dominated by case series, and calls for higher levels of evidence (including RCTs) are gathering pace [20, 21]. Poor reporting 'short circuits' proper critical appraisal prevents inclusion in systematic reviews and meta-analyses, and resulting clinical judgements could be misleading and potentially dangerous.

Previous reviews of surgical RCTs have shown that, in $20 \%$, the conclusions were not justified by the data [22]. Solomon et al. found that the lowest quality RCTs were those that involved a surgical technique, were published in a surgical journal and where a surgeon was the principal author [23].

Research in the field of RCT reporting quality has pointed to the consistent absence of the same key quality data: sample size calculations, randomisation sequence generation method and implementation, post-randomisation verification of balance in known confounders, allocation concealment, blinding, intention-to-treat analysis and participant flow charts. Our study is the first to assess the compliance of recent RCTs in plastic surgery with the CONSORT NPT criteria, and the results support this pattern of poor compliance with a low median CONSORT score of 11.5. This is similar to the CONSORT scores (out of 22) found in earlier work by one of us (RAA), with 11.1 for Urological RCTs, 10.3 for cardiac surgery, 10.9 for general surgery, 11.9 for hepatobiliary, 10.8 for orthopaedic and 12.0 for vascular surgery [19]. Furthermore, the additional CONSORT NPT criteria were severely lacking (Table 3 ). Whilst they are not core criteria, the authors recognise them as important for RCTs of interventions. Poor reporting has also been linked with poor methodology as shown by Taghinia et al. [24] and others [8-12].
Fig. 3 CONSORT score against number of authors

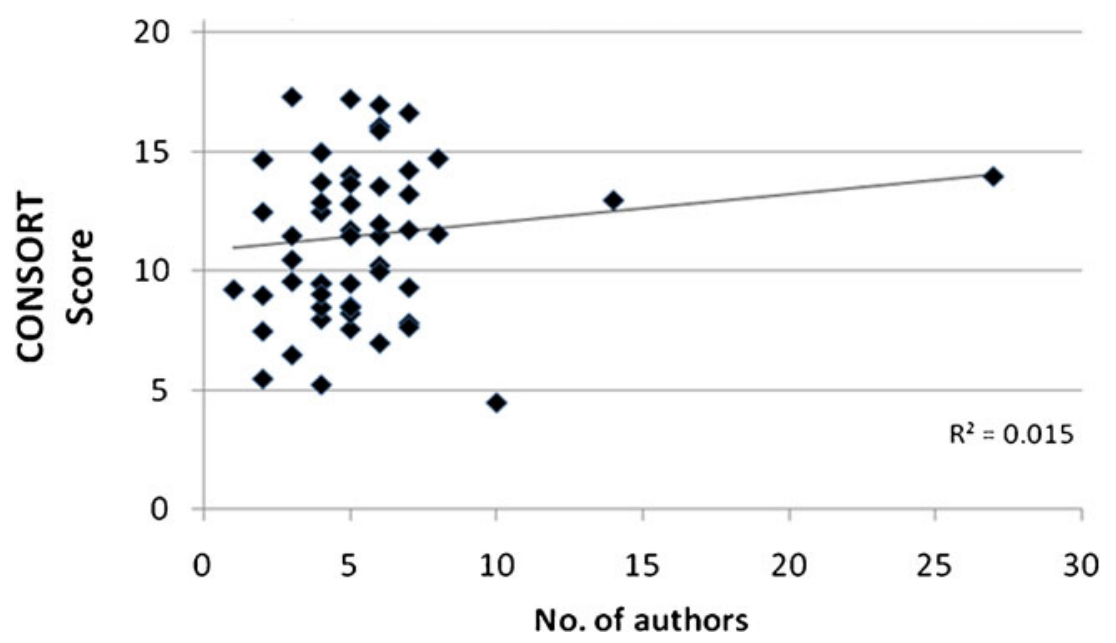


Fig. 4 CONSORT score against ISI 2010 impact factor

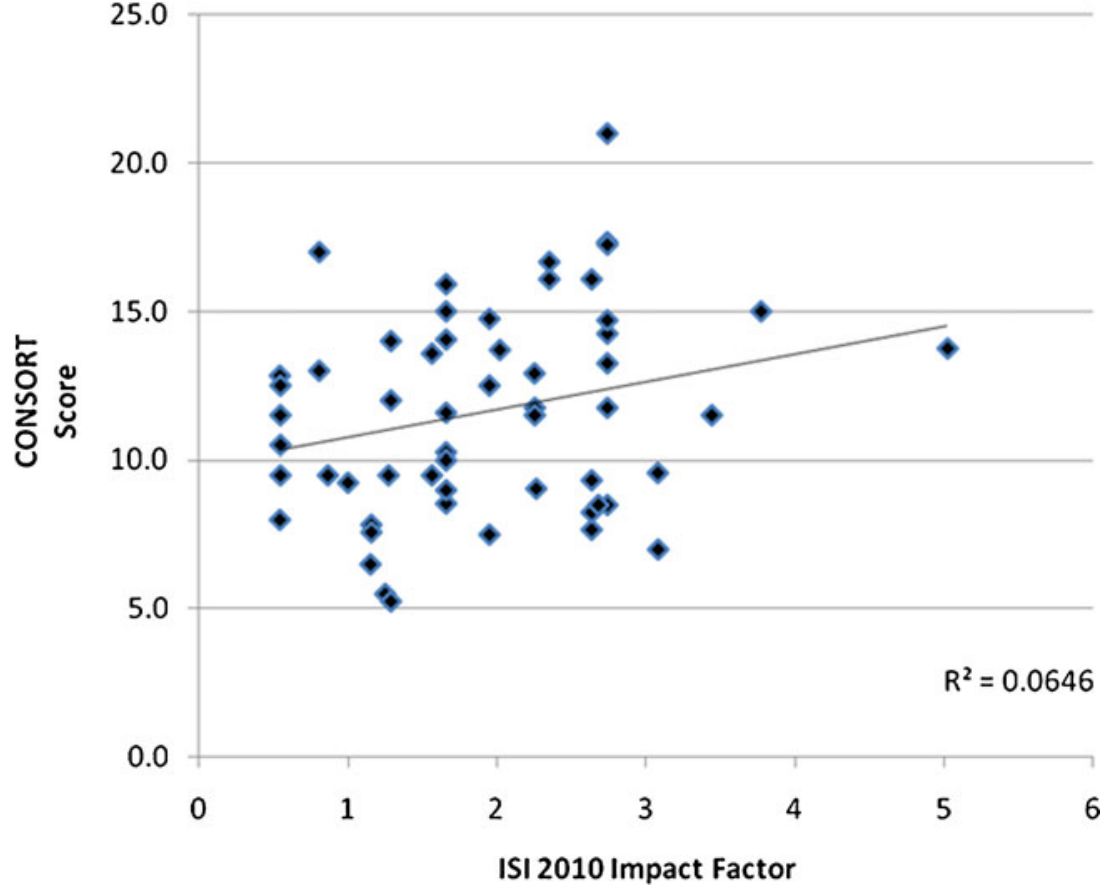

Studies with more authors have been correlated with higher citation levels [25]. One would anticipate that more authors on a study would lead to better reporting quality; however, our research did not support this, consistent with earlier work [19]. There was also no correlation between CONSORT score and the impact factor of the journal in which the RCT was published, again consistent with earlier work by one of us (RA) [19]. The impact factor is heralded by many plastic surgeons and editors [26] as the reflection of increasing journal and article quality. Yet successive studies are now showing that it has no bearing on the quality of reporting of one of the highest levels of evidence - the RCT. Sinha et al. [27] identified the top three ranked surgical journals by impact factor and found that, of 42 RCTs analysed, only $40 \%$ had a Jadad score $\geq 3$ and there was no significant difference between CONSORTendorsing and non-endorsing journals. Our data showed no link between volume of RCTs from a particular geographic region and CONSORT score. This suggests that the problems of poor reporting are indeed global and not confined to a few select countries.

Within plastic surgery specifically, several studies have found that RCTs need improvement in reporting quality. McCarthy et al. [28] analysed level 1 studies in five plastic surgery journals from 1978 to 2009. They found that only
Fig. 5 A bar chart of CONSORT score and number of RCTs against country

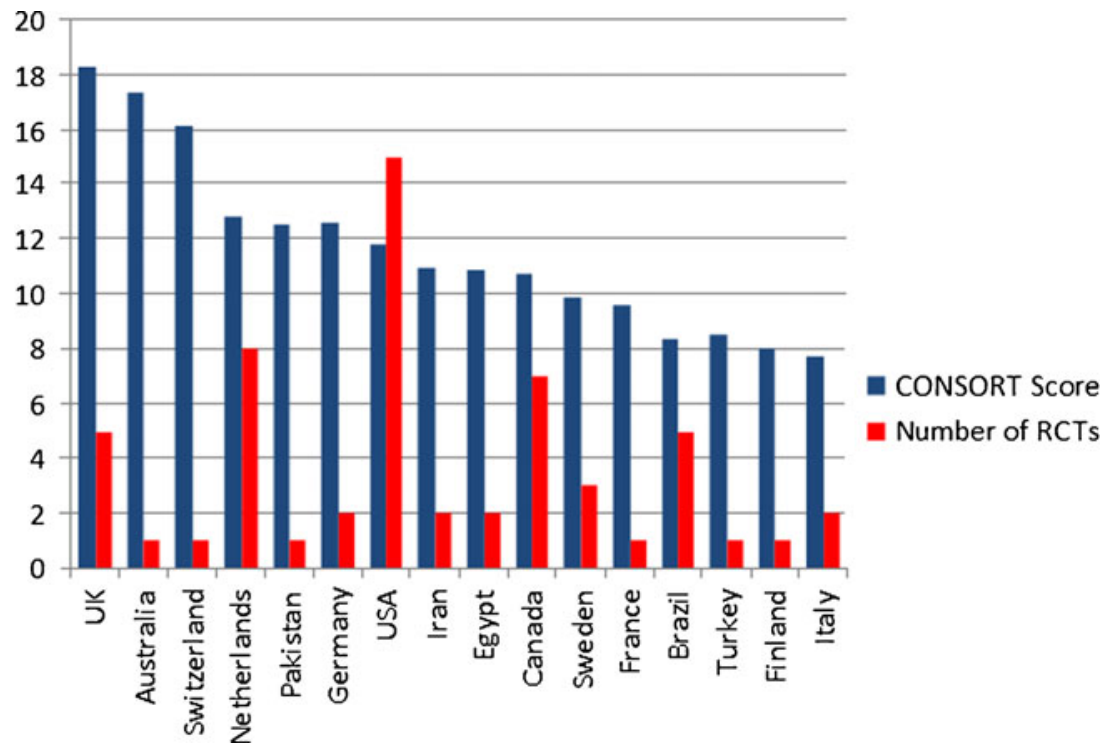


$39 \%$ reported randomisation technique. In their analysis of 96 RCTs in plastic surgery published between 2004 and 2008, Veiga et al. [29] found that $29 \%$ appropriately described allocation concealment. Momeni et al. [30] analysed 172 RCTs from three plastic surgical journals during 1990 2005 and found that only $12 \%$ reported on their allocation concealment and $37 \%$ described participant dropouts. Karri looked at 133 RCTs published across three plastic surgery journals from 1980 to 2004 [31]. Sample size calculation was only reported in $12.8 \%$ of trials, randomisation methodology in $29.3 \%$, allocation concealment in $18.8 \%$, blinding of investigator/assessment in $51.9 \%$ and study limitations in only $33.8 \%$ trials. Veiga Filho et al. in 2005 examined 34 RCTs in plastic surgery and concluded that they were overall of low quality with $59 \%$ scoring two points or less on a Jadad score [32]. In addition, they concluded that the process of randomisation in the studies was appropriately designed and conducted but that authors did not report it. Follow-up work by the same group in 2011 concluded that RCT quality as measured by Jadad criteria had 'significantly increased' [29].

In 2005, the International Committee of Medical Journal Editors implemented a policy [33] that required registration of all clinical trials prior to enrolment of the first patient (part of the aim being a reduction in publication bias from the nonpublication of negative studies). In 2007, this became part of US regulatory requirement with section 801 of the Food and Drug Administration Amendments Act [34]. In 2008, trial registration became an ethical requirement with the updated Declaration of Helsinki mandating it [35]. Despite this, only $16 \%$ of RCTs in our sample stated their trial registry. The low reporting of conflicts of interest, sources of funding and ethical approval is concerning; such information is pivotal scientific and scholarly transparency and integrity.

On the positive side, there was an upward trend in the median CONSORT score, rising three points over the 3-year period 2009-2011. However, since all the CONSORT items are mandatory for reporting, this increase is unlikely to be due to a serious appreciation and compliance with CONSORT specifically. It is more likely to be due to general improvements in reporting that may be occurring or simply random.

The limitations of our study include restriction to the English language, searching only MEDLINE ${ }^{\circledR}$ and analysing papers by publication date rather than submission date, since publication lag times for journals vary. The English language has increasingly become the lingua franca of science with an estimated $80-90 \%$ of papers in scientific journals written in English [36]. This has been coupled with initiatives to offer translation services of key papers [37]. We feel that this strategy would still capture all the relevant papers. Whilst we did not blind our evaluators to the country of origin of the authors, we do not feel there was any inherent bias against a particular country and scores were recorded in a dispassionate manner.
Further work is needed to assess barriers to compliance with CONSORT amongst key stakeholders in the process: authors, journal reviewers and editors, funders, institutions and readers. Meticulous planning, involvement of a trial methodologist, biostatistician and compliance with CONSORT NPT in the eventual paper would be key for those conducting and reporting RCTs. Journal editors and peer reviewers as guardians of the scholarly literature have an important gatekeeper role here $[38,39]$.

We support previous calls for the better education of plastic surgeons at all levels in clinical research methods, evidencebased medicine and improved funding/support of plastic surgical RCTs. McCulloch et al. [40] have called for the deployment of alternative prospective designs, such as interrupted time series studies, to be used when randomised trials are not feasible - we support their call and indeed suggest that registry studies may be useful in some instances.

One solution is to hard-wire compliance with CONSORT by making the checklist a mandatory item for submission if a manuscript is submitted as an RCT. It can also be published as a supplementary item online allowing for greater transparency and scrutiny by readers. Such a policy was adopted by the International Journal of Surgery in January 2013 [41].

\section{Conclusion}

The reporting quality of RCTs in plastic surgery requires improvement. Perceived surrogate markers of quality such as number of authors and impact factor of the journal had no relationship on CONSORT compliance. We suggest ways this could be improved including better education, awareness amongst all stakeholders and hard-wiring compliance through electronic journal submission systems.

Acknowledgments The authors would like to thank Patricia Rey, Information Specialist at Queen Victoria Hospital NHS Foundation for her guidance and meticulous search of the literature to retrieve the initial set of papers.

Conflict of interest RA is on the Editorial Board of the International Journal of Surgery.

\section{References}

1. Jüni P, Altman DG, Egger M (2001) Systematic reviews in health care: assessing the quality of controlled clinical trials. BMJ 323:42-46

2. McCulloch P, Taylor I, Sasako M, Lovett B, Griffin D (2002) Randomised trials in surgery: problems and possible solutions. BMJ 15;324(7351):1448-1451

3. Chan AW, Altman DG (2005) Epidemiology and reporting of randomised trials published in PubMed journals. Lancet 365:11591162 
4. Glasziou P, Meats E, Heneghan C, Shepperd S (2008) What is missing from descriptions of treatment in trials and reviews? BMJ 336:1472-1474

5. Dwan K, Altman DG, Arnaiz JA, Bloom J, Chan AW et al (2008) Systematic review of the empirical evidence of study publication bias and outcome reporting bias. PLoS ONE 3:e3081

6. Schulz KF, Chalmers I, Hayes RJ, Altman DG (1995) Empirical evidence of bias: dimensions of methodological quality associated with estimates of treatment effects in controlled trials. JAMA 273: 408-412

7. Moher D, Pham B, Jones A, Cook DJ, Jadad AR, Moher M et al (1998) Does the quality of reports of randomised trials affect estimates of intervention efficacy reported in metaanalyses? Lancet 352: 609-613

8. Pildal J, Chan A-W, Hróbjartsson A, Forfang E, Altman DG, Gøtzsche PC (2005) Does unclear allocation concealment in trial publications reflect poor methods or poor reporting of adequate methods? Cohort study of trial protocols and corresponding published reports. BMJ 330:1049-1052

9. Juni P, Altman DG, Egger M (2001) Systematic reviews in health care: assessing the quality of controlled clinical trials. BMJ 323:42-46

10. Huwiler-Muntener K, Juni P, Junker C, Egger M (2002) Quality of reporting of randomised trials as a measure of methodologic quality. JAMA 287(21):2801-2804

11. Linde K, Jonas WB, Melchart D, Willich S (2001) The methodological quality of randomised controlled trials of homeopathy, herbal medicines and acupuncture. Int J Epidemiol 30(3):526-531

12. Montori VM, Wang YG, Alonso-Coello P, Bhagra S (2006) Systematic evaluation of the quality of randomised controlled trials in diabetes. Diabetes Care 29(8):1833-1838

13. Begg C, Cho M, Eastwood S, Horton R, Moher D, Olkin I, Pitkin R, Rennie D, Schulz KF, Simel D, Stroup DF (1996) Improving the quality of reporting of randomised controlled trials. The CONSORT statement. JAMA 276(8):637-639

14. Boutron I, Moher D, Altman DG, Schulz KF, Ravaud P, for the CONSORT Group (2008) Methods and processes of the CONSORT Group: example of an extension for trials assessing nonpharmacologic treatments. Ann Intern Med 148:W-60-W-66

15. Agha RA, Camm CF, Edison E, Orgill DP (2013) The methodological quality of randomized controlled trials in plastic surgery needs improvement: a systematic review. J Plast Reconstr Aesthet Surg 66(4):447-452

16. Dechartres A, Charles P, Hopewell S, Ravaud P, Altman DG (2011) Reviews assessing the quality or the reporting of randomized controlled trials are increasing over time but raised questions about how quality is assessed. J Clin Epidemiol 64(2):136-144

17. Moher D, Liberati A, Tetzlaff J, Altman DG, PRISMA Group (2010) Preferred reporting items for systematic reviews and meta-analyses: the PRISMA statement. Int J Surg 8(5):336-341

18. Rhee JS, Daramola OO (2012) No need to fear evidence-based medicine. Arch Facial Plast Surg 14(2):89-92

19. Rohrich RJ (2010) So you want to be better: the role of evidence-based medicine in plastic surgery. Plast Reconstr Surg 126(4):1395-1398

20. Agha R, Cooper D, Muir G (2007) The reporting quality of randomised controlled trials in surgery: a systematic review. Int $\mathrm{J}$ Surg 5(6):413-422

21. Rohrich RJ, Eaves FF 3rd (2011) So you want to be an evidence-based plastic surgeon? A lifelong journey. Plast Reconstr Surg 127(1): $467-472$
22. Solomon MJ, McLeod RS (1998) Surgery and the randomised controlled trial: past, present and future. Med J Aust 169(7):380-383

23. Solomon MJ, McLeod RS, Laxamana A, Devore L (1994) Randomised controlled trials in surgery. Surgery 115:707-712

24. Taghinia AH, Liao EC, May JW Jr (2008) Randomised controlled trials in plastic surgery: a 20-year review of reporting standards, methodologic quality, and impact. Plast Reconstr Surg 122(4): 1253-1263

25. Figg WD, Dunn L, Liewehr DJ et al (2006) Scientific collaboration results in higher citation rates of published articles. Pharmacotherapy 26(6):759-767

26. Rohrich RJ, Sullivan D (2010) The state of your journal: updates and developments - the future of PRS. Plast Reconstr Surg 126:277-285

27. Sinha S, Sinha S, Ashby E, Jayaram R, Grocott MP (2009) Quality of reporting in randomised trials published in high-quality surgical journals. J Am Coll Surg 209(5):565-571.e1

28. McCarthy JE, Chatterjee A, McKelvey TG, Jantzen EM, Kerrigan CL (2010) A detailed analysis of level I evidence (randomized controlled trials and meta-analyses) in five plastic surgery journals to date: 1978 to 2009. Plast Reconstr Surg 126(5):1774-1778

29. Veiga DF, Veiga-Filho J, Pellizzon RF, Juliano Y, Ferreira LM (2011) Evolution of reports of randomized clinical trials in plastic surgery. $\mathrm{J}$ Plast Reconstr Aesthet Surg 64(6):703-709

30. Momeni A, Becker A, Antes G, Diener MK, Blümle A, Stark GB (2008) Evidence-based plastic surgery: controlled trials in three plastic surgical journals (1990-2005). Ann Plast Surg 61(2):221-225

31. Karri V (2006) Randomised clinical trials in plastic surgery: survey of output and quality of reporting. J Plast Reconstr Aesthet Surg 59(8): 787-796

32. Veiga Filho J, Castro AA, Veiga DF, Juliano Y, Castilho HT, Rocha JL, Ferreira LM (2005) Quality of reports of randomized clinical trials in plastic surgery. Plast Reconstr Surg 115(1):320-323

33. ICMJE (2011) Uniform requirements for manuscripts submitted to biomedical journals: publishing and editorial issues related to publication in biomedical journals: obligation to register clinical trials. Available at: http://www.icmje.org/publishing_10register.html. Accessed 26 Dec 2011

34. ClinicalTrials.gov. FDAAA 801 requirements [online]. Available at: http://clinicaltrials.gov/ct2/manage-recs/fdaaa. Accessed 9 Nov 2012

35. World Medical Association (2012) WMA Declaration of Helsinkiethical principles for medical research involving human subjects [online]. Available at: http://www.wma.net/en/30publications/10policies/b3/. Accessed 9 Nov 2012

36. Montgomery S (2004) Of towers, walls, and fields: perspectives on language in science. Science 303(5662):1333-1335

37. Rohrich RJ (2011) So you want to be an international plastic surgeon? Plastic and reconstructive surgery visits China. Plast Reconstr Surg 127(2):981-985

38. Edison E, Agha R, Camm CF (2011) Letter to the editor: no excuse for poor reporting of surgical RCTs. J Orthod 38(4):305-307

39. Edison E, Agha R, Camm CF (2013) Poor quality reporting and surgical RCTs: a wake up call for the international surgical community. Spine 37(7):628

40. McCulloch P, Altman DG, Campbell WB, Flum DR, Glasziou P, Marshall JC et al (2009) No surgical innovation without evaluation: the IDEAL recommendations. Lancet 374(9695):1105-1112

41. International Journal of Surgery (2013) Guide for authors [online]. Available at: http://www.elsevier.com/journals/international-journalof-surgery/1743-9191/guide-forauthors. Accessed 26 Apr 2013 